\title{
Quantitative Analysis of Leg Movement and EMG signal in Expert Japanese Traditional Dancer
}

\author{
Woong Choi ${ }^{1}$, Tadao Isaka ${ }^{2}$, Hiroyuki Sekiguchi ${ }^{1}$ and Kozaburo Hachimura ${ }^{3}$ \\ ${ }^{1}$ Kinugasa Research Organization, Ritsumeikan University \\ ${ }^{2}$ College of Science and Engineering, Ritsumeikan University \\ ${ }^{3}$ College of Information Science and Engineering, Ritsumeikan University \\ Japan
}

\section{Introduction}

Recently, dance movement has been frequently studied using motion capture, but some movements are unable to be analysed by motion data alone. Systematic research of dance movements using several kinds of data captured by simultaneous measurement of body motion and biophysical information are rarely carried out.

In the research literature there are several studies using the analyses of movement through simultaneous measurement of body motion and biophysical information, for instance, the learning environment for sport-form training (Urawaki, 2005), biomechanical analysis of ballet dancers (Humm et al, 1994), and behaviour capture systems (Kurihara et al, 2002), etc. Although there is one study that extracts a target motion from motion captured dance data (Yoshimura et al, 2001), and another where skillfulness of a dancer is investigated by calculating a typical style of the dancing called Okuri (Yoshimura et al, 2004), quantitative analysis on an expert traditional dancer has not been accomplished yet.

We paid attention to leg movements of the lower half of the body. Leg movements of a dancer generate a path of motion, a tempo, and a dance rhythm. In particular, leg movements in Japanese traditional dance allow dancers to express various performances, shift performances, and transfer and retain body weight (Kunieda, 2003).

In the following research, we aim to quantitatively analyse characteristics of leg movement patterns of an expert traditional dancer using simultaneous measurement of body motion and biophysical information (EMG: ElectroMyoGram).

\section{Method of experiment}

We carried out experiments on the leg movements of expert Japanese traditional dancers with simultaneous measurement of body motion and EMG (Choi, 2007).

\subsection{Subject}

The subjects who participated in this experiment are two Hanayagi style dancers; one has forty years experience (Expert $D$ ) and the other has twenty years experience (Skilled $S$ ).

Source: Advances in Human-Robot Interaction, Book edited by: Vladimir A. Kulyukin, ISBN 978-953-307-020-9, pp. 342, December 2009, INTECH, Croatia, downloaded from SCIYO.COM 


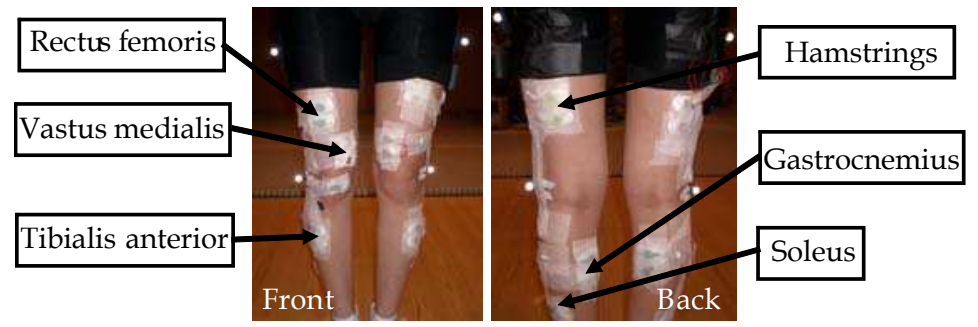

Fig. 1. Attaching place of EMG electrodes.

\begin{tabular}{c|c}
\hline Performance & Role of subject \\
\hline \hline Performance 1 & Guest \\
\hline Performance 2 & Woman expert entertainer \\
\hline Performance 3 & Man entertainer \\
\hline Performance 4 & Warrior \\
\hline Performance 5 & Coachman \\
\hline Performance 6 & Carpenter \\
\hline Performance 7 & Novice entertainer \\
\hline Performance 8 & Narrator \\
\hline
\end{tabular}

Table 1. Experiment performances in Hokushu.

\subsection{Performance}

We measured the traditional Japanese dance named Hokushu using the constructed system. In Hokushu, one dancer plays several roles such as a warrior, a guest, a coachman, a merchant, etc., and acts a total of twenty one performances by oneself. In this research, we measured eight performances from among the twenty-one (see Table 1).

\subsection{Simultaneous measurement of body motion and EMG}

In this research, 32 markers were attached on the body of a subject in order to capture motion data, and 12 EMG electrodes on the front and back of both legs.

Recording EMG signals needs electrodes, an amplifier and a data recording device. Each EMG signal is obtained by A/D converting data amplified by the amplifier. In this research, we used the SYNA ACT MT11 system (NEC Corp.). The amplitude of an EMG signal is almost proportional to the scale of muscle force. This relationship between EMG signal and muscle force can therefore be used to analyse various human body movements. Because the raw EMG signal obtained by the equipment is corrupted by high frequency noise, we have to employ some noise reduction techniques like low pass filtering. Also, we have to convert the raw signal into a signal that is proportional to the activities of the muscles. Rectification of the signal, or the RMS (Root Mean Square) of the signal is usually used for the analysis.

As per the literature on EMG (Choi, (2007)), the attaching place of EMG electrodes is fixed on the following six muscles (see Fig 1): Rectus Femoris (RF), Vastus medialis (VM), Tibialis Anterior (TA), Hamstrings (HA), Gastrocnemius (GAS) and Soleus (SOL). As shown in Table 2, these muscles have functions associated with leg movement. The SOL, VM, and TA muscles are mono-articular muscles. HA, RF, and GAS muscles are bi-articular muscles. 


\begin{tabular}{c|c}
\hline Muscle & Function \\
\hline \hline Rectus Femoris (RF) & $\begin{array}{c}\text { Extension of knee and } \\
\text { flexion of hip }\end{array}$ \\
\hline Vastus medialis (VM) & Extension of knee \\
\hline Tibialis Anterior (TA) & Dorsal flexion of ankle \\
\hline Hamstrings (HA) & $\begin{array}{c}\text { Flexion of knee and } \\
\text { extension of hip }\end{array}$ \\
\hline Gastrocnemius (GAS) & $\begin{array}{c}\text { Plantar flexion of ankle } \\
\text { and flexion of knee }\end{array}$ \\
\hline Soleus (SOL) & Plantar flexion of ankle \\
\hline
\end{tabular}

Table 2. Function of muscle (Perotto, (1994)).

To obtain 3D motion data, the Eagle-Hawk system (Motion Analysis Corp.) at Ritsumeikan University was used. This system incorporates 12 infrared cameras detecting small markers attached to a subject who moves in a $4 \mathrm{~m} \times 4 \mathrm{~m}$ area.

We captured data by adjusting the sampling rate of motion capture to $60 \mathrm{~Hz}$, and EMG measurement to $1200 \mathrm{~Hz}$, and recorded eight performances a total of three times using the simultaneous measurement system.

\section{Result and discussion of experiment}

In this research, we compared the leg movements of an Expert $D$ with that of a Skilled subject $S$ by calculating the center of gravity of the subject's body and a co-contraction of the knee and the ankle using a biomechanical method (Winter, 1990).

In the following, we will describe the result of our experiment on a part of Performance 1 of Hokushu under the condition of a single support phase.

\subsection{Center of gravity}

Firstly, we compared the center of gravity of the two subjects under the condition of a single support phase of both legs in Performance 1.

\subsubsection{Computation of center of gravity}

The center of gravity can be used to indicate transfer and retainment of leg movement. The center of gravity $\left(x_{0}, y_{0}, z_{0}\right)$ of Fig. 2 can be calculated by Eq. (1) (Winter, 1990).

$$
\begin{aligned}
& x_{0}=\frac{m_{1} x_{1}+m_{2} x_{2}+\cdots+m_{n} x_{n}}{M} \\
& y_{0}=\frac{m_{1} y_{1}+m_{2} y_{2}+\cdots+m_{n} y_{n}}{M} \\
& z_{0}=\frac{m_{1} z_{1}+m_{2} z_{2}+\cdots+m_{n} z_{n}}{M}
\end{aligned}
$$

The co-ordinates $\left(x_{1}, y_{1}, z_{1}\right) \cdots\left(x_{n}, y_{n}, z_{n}\right)$ are the locations of center of gravity in each body segment. These locations in each body segment can be calculated by using anthropometric data (segment weight and segment length) as presented by Matsui (Matsui, (1958)). Fig. 2 (b) 


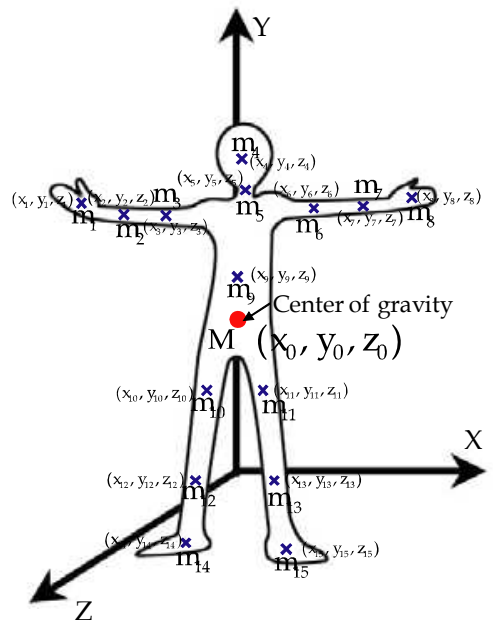

(a)

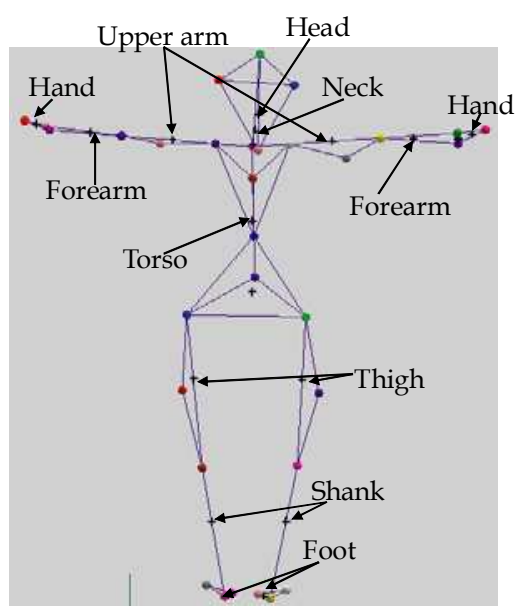

(b)

Fig. 2. Center of gravity. (a) Center of gravity in human body. (b) Center of gravity in each segment.

\begin{tabular}{c|c|c}
\hline Segment & $\begin{array}{c}\text { Segment weight/ } \\
\text { Total body weight }\end{array}$ & $\begin{array}{c}\text { Center of gravity/ } \\
\text { Segment length }\end{array}$ \\
\hline \hline Head & $0.037 \mathrm{M}$ & 0.63 \\
\hline Neck & $0.026 \mathrm{M}$ & 0.50 \\
\hline Torso & $0.487 \mathrm{M}$ & 0.52 \\
\hline Upper arm & $0.0255 \mathrm{M}$ & 0.46 \\
\hline Forearm & $0.013 \mathrm{M}$ & 0.42 \\
\hline Hand & $0.006 \mathrm{M}$ & 0.50 \\
\hline Thigh & $0.1115 \mathrm{M}$ & 0.42 \\
\hline Shank & $0.0535 \mathrm{M}$ & 0.42 \\
\hline Foot & $0.015 \mathrm{M}$ & 0.50 \\
\hline
\end{tabular}

Table 3. Anthropometric data (Matsui, (1958)).

shows the result of our computation for the location of center of gravity in each body segment for subject. The $M$ is a total body weight. $M$ is equal to $m_{1}+m_{2}+\cdots+m_{n}$. The values $\left(m_{1}, \cdots, m_{n}\right)$ are the segment weight in each body segment. In this experiment, we use the anthropometric data of Japanese woman (see Table 3).

\subsubsection{Center of gravity on Performance 1}

Fig. 3 shows the center of gravity data obtained during Performance 1 of Expert $D$ and Skilled $S$.

Fig. 3 (a) and (c) show leg movement under a condition of a single support phase of the right leg during Performance 1 . Subjects maintain their body weight with the right leg, while the left leg is swinging. Fig. 3 (b) and (d) show leg movement under a condition of a single support phase of the left leg. Subjects retain their body weight with the left leg, while 

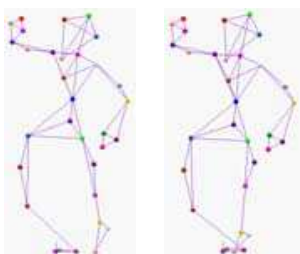

(a)

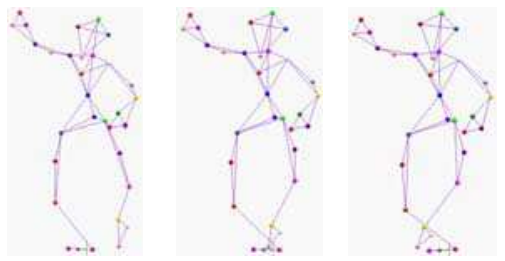

(c)

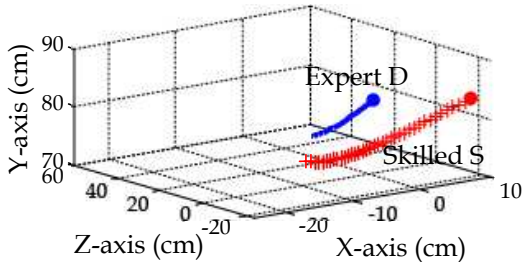

(e)

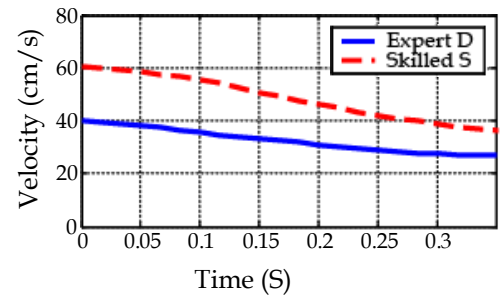

(g)

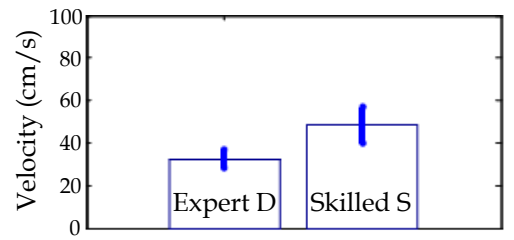

(i)

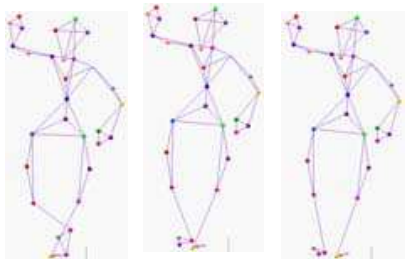

(b)

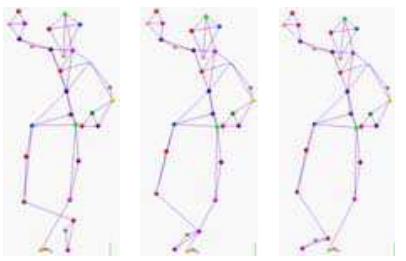

(d)

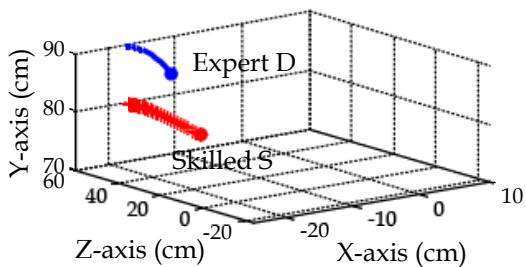

(f)

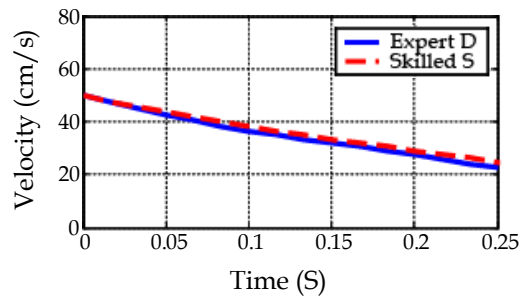

(h)

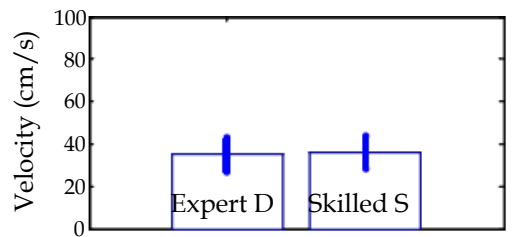

(j)

Fig. 3. Center of gravity on Performance 1. (a) Single support phase: $D$ (right). (b) Single support phase: $D$ (left). (c) Single support phase: $S$ (right). (d) Single support phase: $S$ (left). (e) Center of gravity in body (right). (f) Center of gravity in body (left). (g) Velocity of CG (right). (h) Velocity of CG (left). (i) Average of velocity of CG (right). (j) Average of velocity of CG (left). 
the right leg is swinging. The two subjects have no significant difference in leg movement during the single support phases.

Fig. 3 (e) and (f) show the transfer of the center of gravity of Expert $D$ and Skilled $S$. Points indicated by "•" in (e) and (f) show the start point of the single support phase of both legs during Performance 1 . The two subjects exhibit leg movement with lower center of gravity under a condition of single support phase of the right leg in (e). Skilled $S$ has more transfer of center of gravity than that of Expert $D$. In (f), the two subjects show leg movement which raised the center of gravity. When we consider the fact that the body height of the two subjects are almost the same (about $153 \mathrm{~cm}$ ), we notice that Expert $D$ raised her center of gravity approximately $10 \mathrm{~cm}$ higher than that of Skilled $S$.

Fig. $3(\mathrm{~g})$ and $(\mathrm{h})$ show the velocity of center of gravity of the two subjects under the single support phase of both legs in Performance 1. In (g), Skilled $S$ has a velocity variation of center of gravity of approximately $10-20 \mathrm{~cm} / \mathrm{s}$ greater than that of Expert $D$. In $(\mathrm{h})$, the velocities of center of gravity of both subjects are almost the same.

Fig. 3 (i) and (j) show the average velocity of center of gravity under the single support phase of both legs. In (i), Skilled $S$ has an average velocity and a standard deviation larger than those of Expert $D$. In (j), the two subjects have almost the same velocity and standard deviation. Expert $D$ dances slowly, about $40 \mathrm{~cm} / \mathrm{s}$, during the single support phase of Performance 1, but Skilled $S$ dances faster at $40-60 \mathrm{~cm} / \mathrm{s}$ velocity.

Based on the above data, we found that Skilled $S$ had more center of gravity transfer and velocity variation than Expert $D$ during the single support phase of Performance 1.

\subsection{Movement of knee and ankle}

Secondly, we analysed the characteristics of leg movement of the subjects Expert $D$ and Skilled $S$ by comparing not only the angles of the knees and ankles but also EMG data of muscles used during their movement in Performance 1.

\subsubsection{Knee movement}

Fig. 4 shows the angle of the knees and the RMS of the EMG during Performance 1. Fig. 4 (a) and (c) show movements of the right knee of the two subjects under the single support phase of the right leg. Fig.4 (b) and (d) show movements of the left knee during single support phase of the left leg. There is no significant difference in movement of the knees of two subjects during the single support phases.

Fig. 4 (e) and (f) show the angle of the knees of both legs of the two subjects during the single support phase. The angle variation of the knee in (e) indicates that the subjects use knee flexion to lower the leg. The difference of angle variation of the knee between the two subjects was approximately $10-20^{\circ}$. This is not a significant difference. Angle variation of the knees in (f) indicates that the subjects use knee extension to raise the leg.

Fig. 4 (g) and (h) show the RMS values of the RF muscle for Expert $D$ and Skilled $S$. During the single support phase of the right leg in (g), the RF muscles of Expert $D$ and Skilled $S$ discharged approximately $200 \mathrm{mV}$ and $400 \mathrm{mV}$, respectively. Compared to Expert $D$, the RF muscle of Skilled $S$ discharged approximately twice the EMG level to support the body with lowered center of gravity. During the single support phase of the right leg in (h), the RF muscles of Expert $D$ and Skilled $S$ discharged approximately $100 \mathrm{mV}$ and $200 \mathrm{mV}$, respectively. Once again, the RF muscle of Skilled $S$ discharged approximately double the EMG signal than that of Expert $D$. 


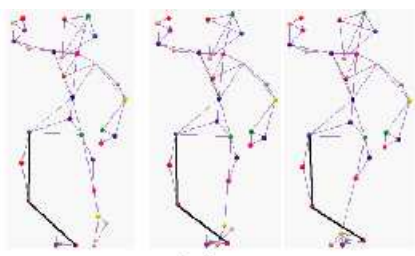

(a)

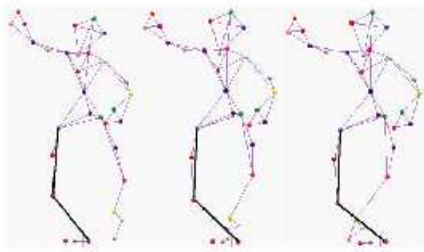

(c)

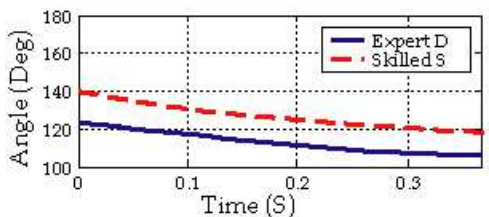

(e)

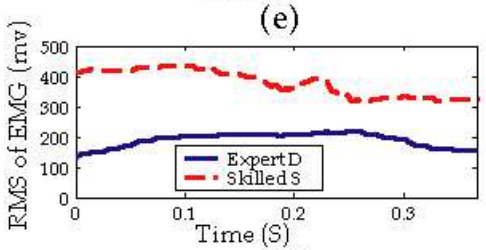

(g)

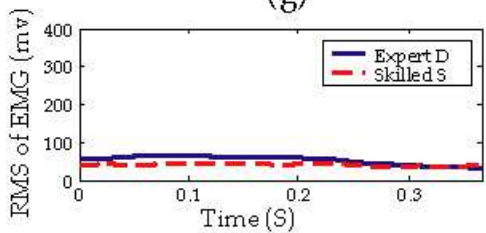

(i)

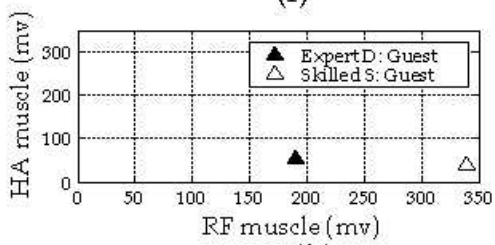

(k)

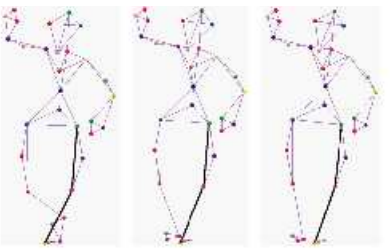

(b)

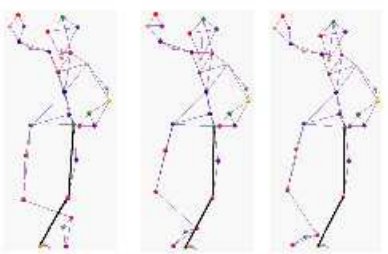

(d)

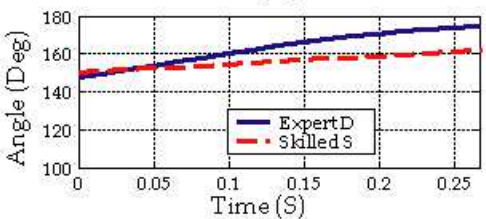

(f)

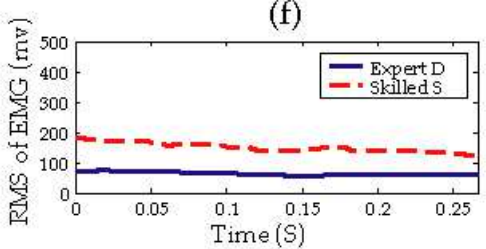

(h)

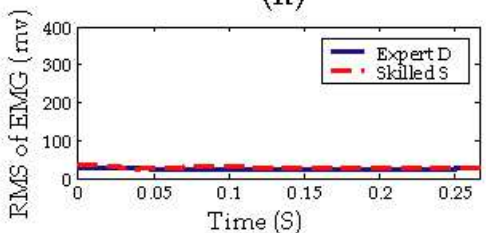

(j)

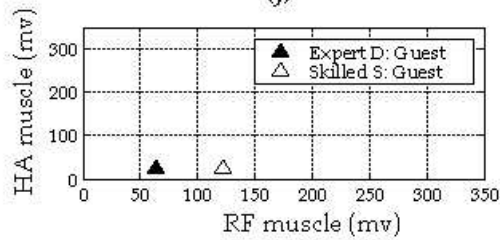

(1)

Fig. 4. Angle of knee and RMS of EMG on Performance 1. (a) Knee: $D$ (right). (b) Knee: $D$ (left). (c) Knee: $S$ (right). (d) Knee: $S$ (left). (e) Angle of knee (right). (f) Angle of knee (left). (g) RMS of RF(right). (h) RMS of RF (left). (i) RMS of HA (right). (j) RMS of HA (left). (k) Average of RMS (right). (l) Average of RMS (left). 
Fig. 4 (i) and (j) show the RMS values of the HA muscles of Expert D and Skilled S. Under the single support phase of the right leg in (i), the HA muscle produces less EMG than the RF muscle. In order to lower the leg movement, the subjects are able to flex the knee by using a smaller muscle force due to gravity. The RF muscle antagonistic to HA muscle in knee is activated to support the body weight. Also, the HA muscle produces less EMG than the RF muscle during the single support phase of the left leg in (j). The RF muscle is activated to raise the leg with knee extension.

The $X$ and $Y$ axes of Fig. 4 (k) and (l) show the RMS values of EMG signal from the RF and HA muscles. RF and HA muscles are antagonistic muscle pairs of the knee. Expert $D$ takes a balance of EMG activity between the two antagonist muscles when compared with Skilled $S$ during the single support phase of the right leg in (k). Also, Expert $D$ takes balance of EMG activity compared to Skilled $S$ during the single support phase of left leg in (l).

Since Skilled $S$ has a larger transfer and velocity variation of center of gravity than Expert $D$ in (e) of Fig. 3, we noticed that when flexing the knee the RF muscle of Skilled $S$ had more EMG activity than that of Expert $D$ for supporting the body.

\subsubsection{Ankle movement}

Next, Fig. 5 shows the angle of the ankle and the RMS of the EMG signal during Performance 1. Fig. 5 (a) and (c) show the movement of the ankle of Expert $D$ and Skilled $S$ during the single support phase of the right leg. Fig. 5 (b) and (d) show the movement of the ankle during the single support phase of the left leg.

Fig. 5 (e) and (f) show ankle angle of the two subjects during the single support phase of both legs. Ankle angle variation in (e) indicates that the subject used the ankle dorsal to lower the leg. The difference between ankel angle variation between the two subjects was approximately $10^{\circ}$. The angle variation of the knee in (f) indicates that the subjects used ankle plantar flexion to raise the leg.

Fig. $5(\mathrm{~g})$ and $(\mathrm{h})$ show the EMG RMS value of the TA muscle of Expert $D$ and Skilled $S$. The TA muscles of both subjects produced approximately $100 \mathrm{mV}$ during the single support phase of the right leg in (g). During the single support phase of the right leg in (h), the TA muscle of Expert $D$ and Skilled $S$ produced approximately $50 \mathrm{mV}$ and $50-200 \mathrm{mV}$, respectively. The TA muscle of Skilled $S$ also produced approximately double the EMG signal compared to Expert $D$. After maintaining the EMG discharge of approximately $200 \mathrm{mV}$ in the TA muscle during the first 0.1 second, Skilled $S$ reduced the discharge of EMG by approximately $50 \mathrm{mV}$ during the single support phase of left leg. Expert $D$ maintained the EMG discharge of approximately $50 \mathrm{mV}$. Therefore, we conclude that Skilled $S$ used more muscle force for acting Performance 1 .

Fig. 5(i) and (j) show the RMS value of the SOL muscles of Expert $D$ and Skilled $S$. The SOL muscle EMG discharge was maintained at approximately $100 \mathrm{mV}$ during the single support phase of the right leg in (i). Also, the EMG discharge of the SOL muscle was maintained at approximately $50 \mathrm{mV}$ during the single support phase of the left leg in (j).

The $X$ and $Y$ axies of Fig. $5(\mathrm{k})$ and (l) show the EMG RMS values of the TA and SOL muscles. TA and SOL muscles are antagonistic muscles of the ankle. Expert $D$ and Skilled $S$ took a balance of muscle activity between two antagonistic muscles of ankle during the single support phase of the right leg in (k). However, Expert $D$ took a balance of EMG activity of ankle compared to that of Skilled $S$ during the single support phase of the left leg in (l). In this result, Expert $D$ maintained the EMG activity of the ankle muscle during the single support phase. In particular, Expert $D$ takes a balance of EMG activity between two antagonist muscles of the ankle and knee for the single support phase as shown in Figs. 4 and 5. 


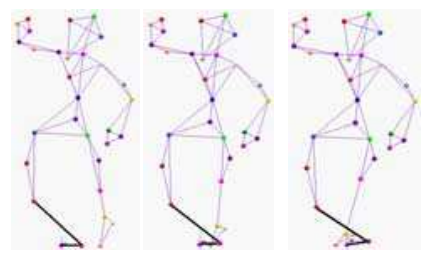

(a)

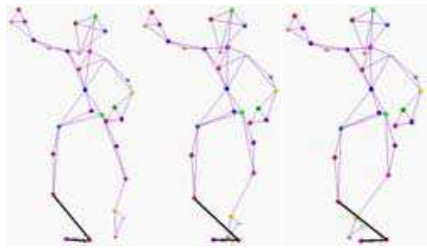

(c)

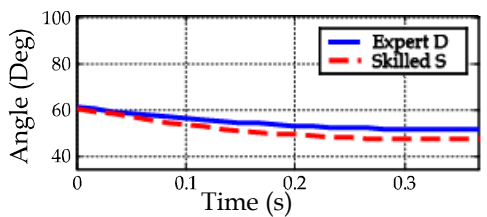

(e)

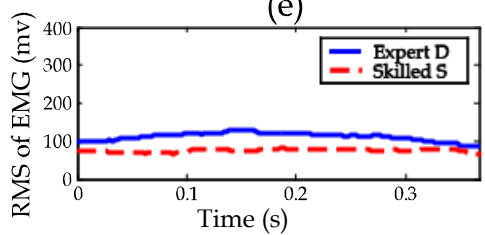

(g)

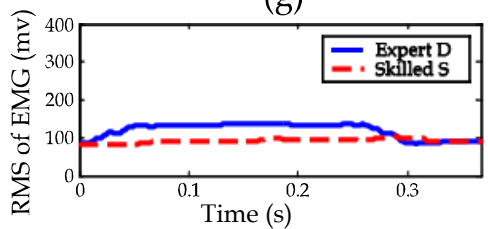

(i)

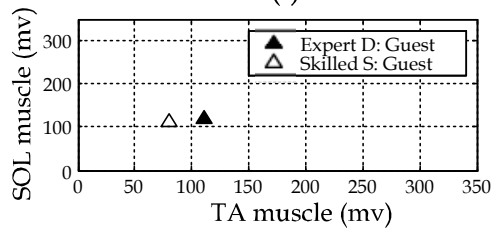

(k)

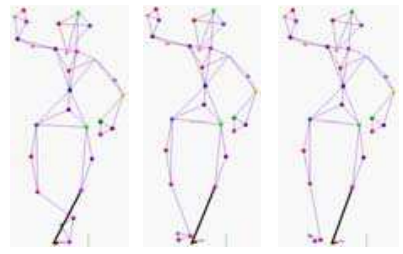

(b)

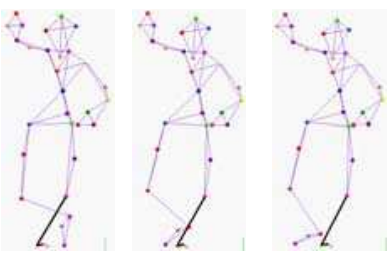

(d)

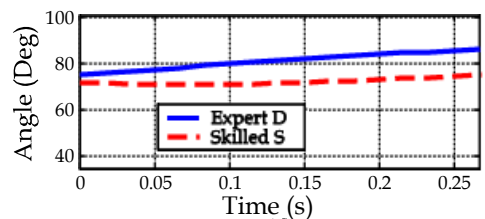

(f)

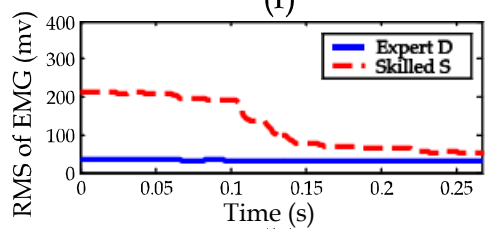

(h)

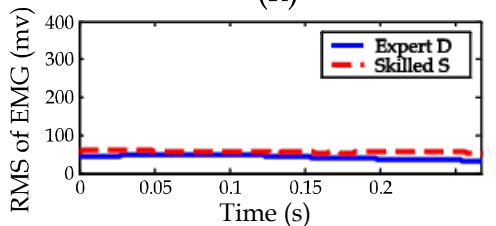

(j)

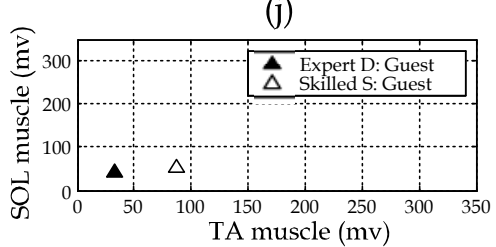

(1)

Fig. 5. Angle of ankle and RMS of EMG on Performance 1. (a) Ankle: $D$ (right). (b) Ankle: $D$ (left). (c) Ankle: $S$ (right). (d) Ankle: $S$ (left). (e) Angle of ankle (right). (f) Angle of ankle (left). (g) RMS of TA (right). (h) RMS of TA (left). (i) RMS of SOL (right). (j) RMS of SOL (left). (k) Average of RMS (right). (l) Average of RMS (left). 


\subsection{Efficiency of co-contraction of the knee and ankle}

Thirdly, we compared the efficiency of leg movement of the two subjects during the single support phase in Performance 1. The efficiency of leg movement is calculated by observing co-contraction of the two antagonistic muscles of the knee and ankle. The efficiency of cocontraction of antagonistic muscles can be determined by the following equation (Winter, 1990) (see Fig. 6).

$$
\text { Co }- \text { contraction }=2 \times \frac{A \cap B}{A \cup B} \times 100
$$

We compute the efficiency of leg movement via Eq. (2). Table 4 shows the co-contraction of the knee and ankle of two subjects during Performance 1 of Hokushu. Expert D had high cocontraction that was approximately $10-20 \%$ greater than Skilled $S$. When we take into consideration that the EMG activity of Expert $D$ was less than Skilled $S$, we notice that Expert $D$ is performing leg movement more efficiently during the single support phase of both legs.

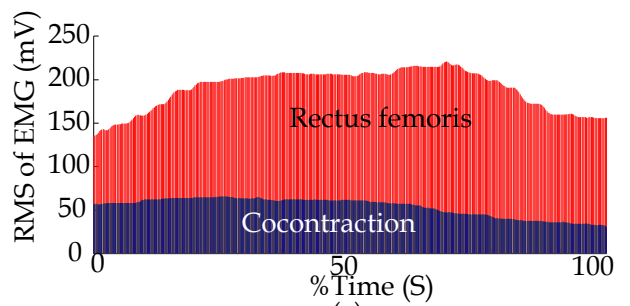

(a)

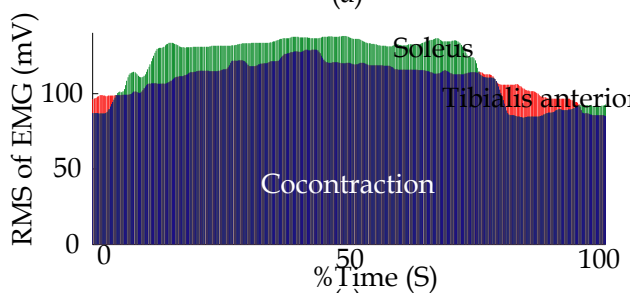

(c)

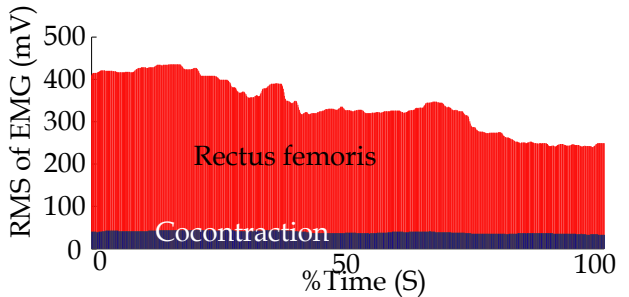

(b)

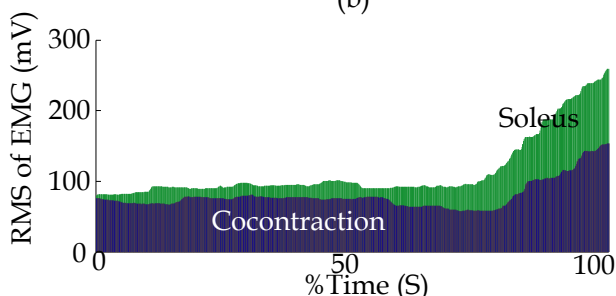

(d)

Fig. 6. Co-contraction of antagonistic muscles during single support phase of right leg. (a) Co-contraction of knee (Expert D). (b) Co-contraction of knee (Skilled S) . (c) Co-contraction of ankle (Expert $D)$. (d) Co-contraction of ankle (Skilled $S$ ).

\begin{tabular}{c|c|c|c|c}
\hline \multirow{2}{*}{} & \multicolumn{2}{|c|}{$\begin{array}{c}\text { Single support } \\
\text { phase (right) }\end{array}$} & \multicolumn{2}{c}{$\begin{array}{c}\text { Single support } \\
\text { phase (left) }\end{array}$} \\
\cline { 2 - 5 } & Knee & Ankle & Knee & Ankle \\
\hline \hline Expert $\boldsymbol{D}$ & $41 \%$ & $77 \%$ & $53 \%$ & $86 \%$ \\
\hline Skilled $S$ & $25 \%$ & $76 \%$ & $36 \%$ & $83 \%$ \\
\hline
\end{tabular}

Table 4. Co-contraction of knee and ankle on Performance 1 of Expert $D$ and Skilled $S$. 

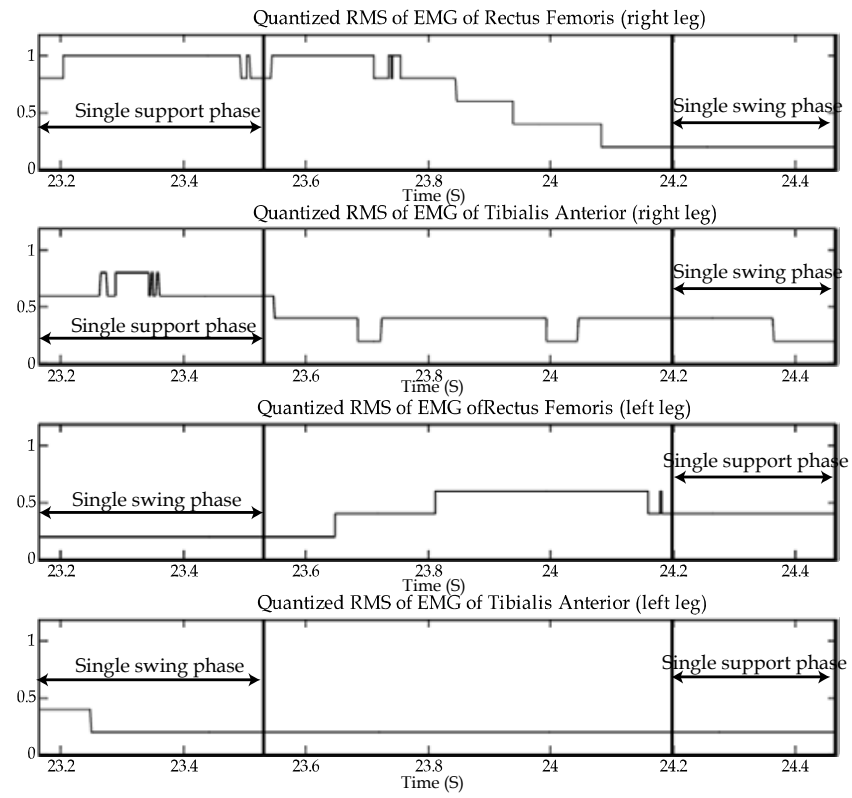

(a)
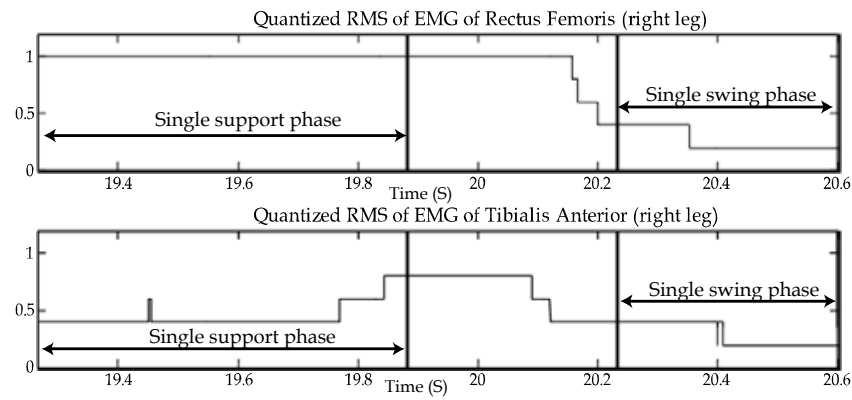

Quantized RMS of EMG of Rectus Femoris (left leg)

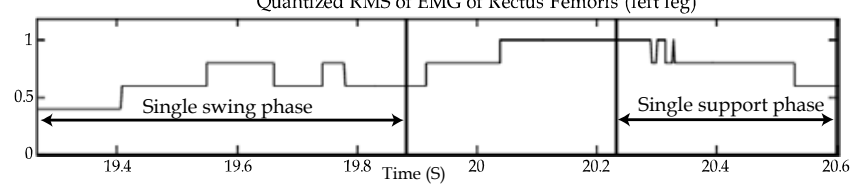

Quantized RMS of EMG of Tibialis Anterior (left leg)

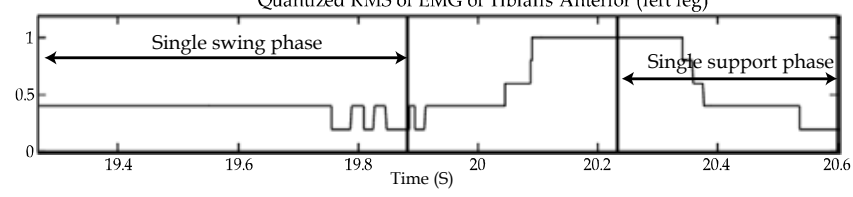

(b)

Fig. 7. Quantized RMS of EMG signal on single support phase during Performance 1. (a) Single support phase of Expert D. (b) Single support phase of Skilled $S$. 


\subsection{Visualization of the single support phase of Performance 1}

Finally, we visualize the leg movement of the two subjects during Performance 1 using CG character animation.

Fig. 7 (a) and (b) show the quantized RMS values of the EMG signal for the RF and TA muscles of both legs during single support phase. We used the RMS data of the RF muscle in (g) and (h) of Fig. 4, and the RMS data of the TA muscle in (g) and (h) of Fig. 5. The RMS data is quantized to 5 levels. We then made a CG character animation using an OpenGL program, colouring the character's legs in accordance with the quantized RMS data. At the same time, we show the leg movement of the single swing phase versus the single support phase of both legs in Fig. 7 (a) and (b).

Fig. 8 (a) and (b) show snapshots of the CG character animation with generated colours based on the single support phase of both legs. During high EMG activity, the colour becomes deeper than during low EMG activity, in proportion to the EMG signal level as shown in Fig. 8. We found that the differences in leg movement between the Expert $D$ and Skilled $S$ were more obvious when displaying EMG information via the CG character.

As shown in Fig. 8 (a) and (b), we notice that the RF and TA muscles of both legs of Skilled $S$ on are activated to act Performance 1 compared to Expert $D$. Expert $D$ had less EMG activity than Skilled $S$ for acting the single swing movement during the single support phase.

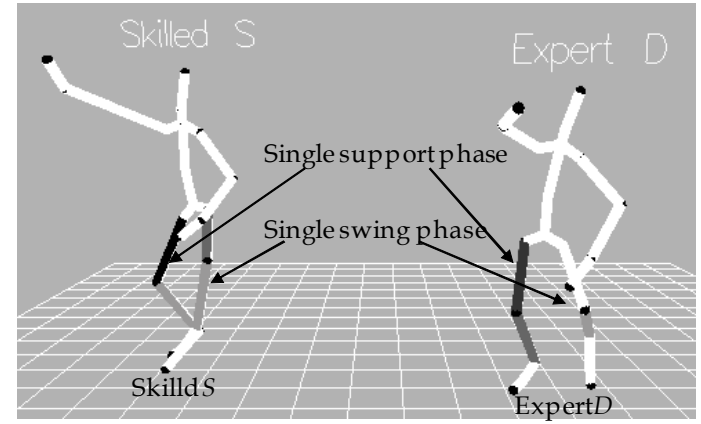

(a)

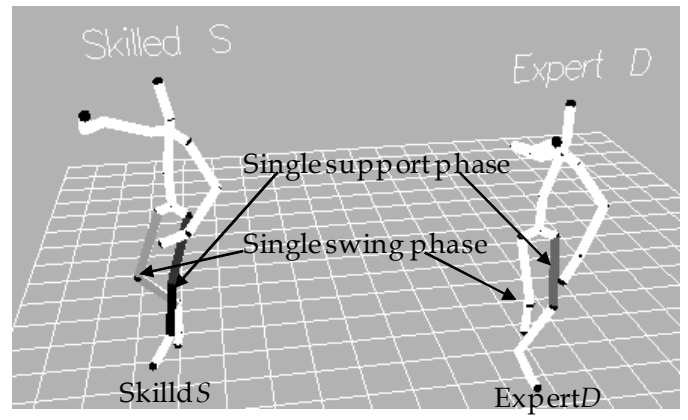

(b)

Fig. 8. CG character animation of body motion and EMG signal on single support phase during Performance 1. (a) Single support phase of right leg. (b) Single support phase of left leg. 


\section{Conclusion and future work}

In this research, we performed quantitative analysis of leg movement patterns of an expert traditional dancer using simultaneous measurement of body motion and leg muscle EMG.

As a result, we verified that Expert $D$, who has a forty-year career as a Japanese traditional dancer, has the effective co-contraction of antagonistic muscles of the knee and ankle and less center of gravity transfer than Skilled $S$, who has only a twenty-year career. Therefore, Expert $D$ can efficiently perform dance leg movements with less EMG activity than Skilled $S$. Our research can help dancers and researchers of dance by providing new information on dance movement that cannot be analysed via motion capture alone.

In the future, we will measure the leg movement control of veteran dancers, especially for quantitatively comparing leg movement skills, by recording the leg movements of masters and beginners. Furthermore, we will investigate leg movement skill by simultaneously using EMG equipment and a force plate.

\section{Acknowledgment}

We would like to thank Ms. Daizo Hanayagi and Ms. Souko Hanayagi for co-operating with us in the motion capturing experiment with EMG measurement. We also thank Prof. Yuka Marumo and Prof. Mamiko Sakata for providing us valuable advice about traditional Japanese dance.

This research has been conducted partly by the support of the Global COE Program, the Open Research Center Program, and the Grant-in-Aid for Scientific Research No. (B)16300035, and No. (C)20500105 all from the Ministry of Education, Science, Sports and Culture.

\section{References}

Urawaki, K. (2005). A Learing System for Sport Form using Visualization of Biophysical Information, Master's Thesis, Nara Institute of Science and Technology, Japan, (in Japanese)

Humm, J.R. ; Harris, G.F. \& Raasch, W.G. (1994). A Biomechanical Analysis Of Ballet Dancers On Pointe, In Proceedings of the 16th Annual International Conference of the IEEE on Engineering in Medicine and Biology Society, pp. 374-375, 10.1109/IEMBS.1994.411997

Kurihara, K. ; Hoshino, S. ; Yamane, K. \& Nakamura, Y. (2002). Optical motion capture system with pan-tilt camera tracking and realtime data processing, In Proceedings of the IEEE International Conference on Robotics and Automation, pp. 1241-1248, 10.1109/ROBOT.2002.1014713

Yoshimura, M. ; Mine, N. ; Kai, T. \& Yoshimura, I. (2001). Quantification of Characteristic Features of Japanese Dance for Individuality Recognition, In Proceedings of 10th IEEE on Robot and Human Interactive Communication, pp. 188-193, 10.1109/ROMAN.2001.981900

Yoshimura, M. ; Kojima, K. ; Hachimura, K.; Marumo, Y. \& Kuromiya, A. (2004). Quantification and recognition of basic motion okuri in Japanese traditional dance, In Proceedings of 13th IEEE on Robot and Human Interactive Communication, pp. 205210, 10.1109/ROMAN.2004.1374757 
Kunieda, T. (2003). Body of JIUTA MAI with profound Japanese cul-ture, In Proceedings of the Inter-Congress of IUAES2002, pp. 24-31.

Choi, W. ; Isaka, T. ; Sakata, M. ; Tsuruta, S. \& Hachimura, K. (2007). Quantification of Dance Movement by Simultaneous Measurement of Body Motion and Biophysical Information, International Journal of Automation and Computing, vol. 04, no. 1, pp. 1-7

Perotto, A. O. (1994). Anatomical Guide for the Electromyographer: The Limbs and Trunk, Charles C. Thomas Publisher

Wirhed, R. (1984). Athletic ability and the anatomy of motion, Wolfe Medical Publications

Winter, David A. (1990). Biomechanics and Motor Control of Human Movement, Wiley Interscience

Matsui, H. (1958). Exercise and center of gravity in human body, Taiikuno Kagakusha, (in Japanese) 


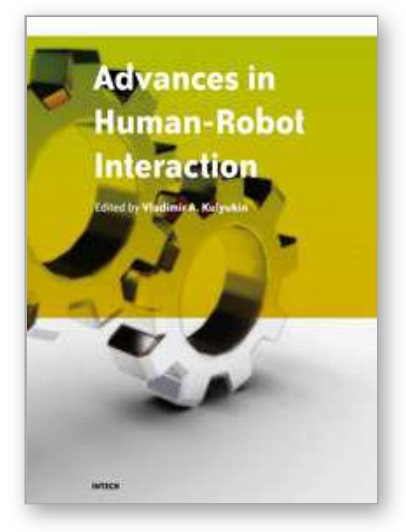

\author{
Advances in Human-Robot Interaction \\ Edited by Vladimir A. Kulyukin
}

ISBN 978-953-307-020-9

Hard cover, 342 pages

Publisher InTech

Published online 01, December, 2009

Published in print edition December, 2009

Rapid advances in the field of robotics have made it possible to use robots not just in industrial automation but also in entertainment, rehabilitation, and home service. Since robots will likely affect many aspects of human existence, fundamental questions of human-robot interaction must be formulated and, if at all possible, resolved. Some of these questions are addressed in this collection of papers by leading HRI researchers.

\title{
How to reference
}

In order to correctly reference this scholarly work, feel free to copy and paste the following:

Woong Choi, Tadao Isaka, Hiroyuki Sekiguchi and Kozaburo Hachimura (2009). Quantitative Analysis of Leg Movement and EMG signal in Expert Japanese Traditional Dancer, Advances in Human-Robot Interaction, Vladimir A. Kulyukin (Ed.), ISBN: 978-953-307-020-9, InTech, Available from: http://www.intechopen.com/books/advances-in-human-robot-interaction/quantitative-analysis-of-legmovement-and-emg-signal-in-expert-japanese-traditional-dancer

\section{INTECH}

open science | open minds

\section{InTech Europe}

University Campus STeP Ri

Slavka Krautzeka 83/A

51000 Rijeka, Croatia

Phone: +385 (51) 770447

Fax: +385 (51) 686166

www.intechopen.com

\section{InTech China}

Unit 405, Office Block, Hotel Equatorial Shanghai

No.65, Yan An Road (West), Shanghai, 200040, China 中国上海市延安西路65号上海国际贵都大饭店办公楼405单元

Phone: +86-21-62489820

Fax: +86-21-62489821 
(C) 2009 The Author(s). Licensee IntechOpen. This chapter is distributed under the terms of the Creative Commons Attribution-NonCommercialShareAlike-3.0 License, which permits use, distribution and reproduction for non-commercial purposes, provided the original is properly cited and derivative works building on this content are distributed under the same license. 